\title{
FEASIBILITY EXPLORATION OF "MULTI-CONFORMITY" UNDER THE BACKGROUND OF BIG DATA
}

\author{
LEI Yong, WANG Lihui, WANG Zhihong
}

Guizhou University of Engineering Science, School of Mining Engineering, Bijie Guizhou 551700, China, 546743737@qq.com

KEY WORDS: multi-conformity, projection deformation, Big data, CGCS2000, urban independent coordinate system

\begin{abstract}
:
"Multi-conformity" requires the unification of surveying and mapping coordinate system. The Ministry of Natural Resources calls for the unified use of CGCS2000 coordinates in natural resources systems. Therefore, "multi-conformity" can only be carried out in the CGCS2000 coordinate system. In Bijie Experimental Area, the projection deformation of CGCS2000 coordinate system is far greater than the requirement of $2.5 \mathrm{~cm} / \mathrm{km}$ stipulated in the urban surveying, so it can not be directly used in urban construction, and its own independent coordinate system must be established. In order to resolve this contradiction and meet the requirements of "multi-conformity", Ministry of Natural Resources and urban construction, to explore the transformation of geographic information data under CGCS2000 coordinate system into urban independent coordinate system data in time by using the cloud computing function of big data under the condition of unification of basic data to meet the needs of engineering construction and to serve the economic construction of Bijie Experimental Area.
\end{abstract}

\section{INTRODUCTION}

Bijie Experimental Area was proposed by Hu Jingtao, then Secretary of Guizhou Provincial Party Committee, and approved by the State Council of the People's Republic of China as an experimental area of "development and poverty alleviation, ecological construction and population control ". It is an area concerned by the former presidents Hu Jingtao and the present president $\mathrm{Xi}$ Jinping and his father. The central urban area is located in the $105^{\circ} 10^{\prime}-40^{\prime}$ east Longitude, $27^{\circ} 05^{\prime}-25^{\prime}$ 'north latitude, with an area of 964 square kilometers. The highest land height is 2026 meters, the lowest height is 1148 meters, the maximum height difference is 878meters. In December 2013, Chinese Communist Party Central Committee proposed that a unified spatial planning system should be established, the boundaries of urban development should be limited, the red line of urban ecology should be delineated, and a blueprint should be achieved to the end. The 13th Five-Year Plan outline of the state clearly requires that the municipal and county administrative regions should be taken as units, and the main functional areas should be planned as the basis for coordinating all kinds of spatial planning so as to promote "multi-planning and integration". At the same time, the Ministry of Natural Resources stipulates that since July 1st, 2018, the CGCS2000 coordinate system will be all-around used in the natural resources system.

\section{NECESSITY OF "MULTI-CONFORMITY"}

\subsection{Reasons for "Multi-conformity"}

\subsubsection{Reasons for Multiple Coordinate Systems}

The projection deformation of CGCS2000 coordinate system will reach $20 \mathrm{~cm} / \mathrm{km}$ under the natural geographical conditions of the central city of Bijie Experimental Area, which is much larger than the requirement of $2.5 \mathrm{~mm} / \mathrm{km}$ stipulated in the urban survey code. In order to meet the requirements of urban surveying standards and promote the development of Bijie Experimental Area project construction, it is necessary to establish an independent coordinate system .
Due to historical reasons, surveying and mapping technical force is very weak in Bijie, each department is independent of each other and has established their own plane coordinate system, such as independent coordinate system, Yachi coordinate system and vocational education city coordinate system, and the technical background is weak too, which can not effectively control the side-length projection deformation and they also lack of the parameter of independent coordinate system. At the same time, due to the differences between each department, there coexists different Surveying and mapping data such as Beijing coordinate system in 1954 and Xi'an coordinate system in 1980, which results in the chaos of the basis of Surveying and mapping in Bijie City, which seriously restricts the economic construction development of Bijie City .

In order to solve the problem of projection deformation, in 2014, with the approval of the Bijie Municipal People's Government and the technical strength of the First Surveying and Mapping Institute of Guizhou Province ,Bijie Urban and Rural Planning Bureau took the lead in establishing the independent coordinate system of Bijie urban center, which met the requirements of Engineering construction.

\subsubsection{Causes of Multiple Planning}

Land use planning, urban and rural planning, national economy and social development planning and ecological environment protection planning belong to different departments. Their planning objectives, standards, methods and deadlines are different, and their requirements for coordinate plane and elevation accuracy are different too. At the same time, because the area of each basic planning is more than 6 square kilometers, they belong to secret-related materials. In order to secrecy and reduce all kinds of links in dealing with confidential data or data among different departments have not been shared, each department collects basic data according to its own needs, so the basic data coordinate system appeared. But situations of Multi-rules parallel because of the scale of various planning are not consistent. 


\subsection{Contradictions of "Multi-conformity" in Geographic Information Data Acquisition}

The accuracy of plane coordinate of national economy and social development planning and ecological environment protection planning is relatively low, and there is no big difference in which surveying and mapping benchmark is used. CGCS2000 coordinate system can be used uniformly according to the requirements of the Ministry of Natural Resources. The CGCS2000 coordinate system is adopted in land use planning according to the requirements of the Ministry of Natural Resources. However, urban and rural planning is closely related to urban construction, and it needs to meet the measurement criteria of urban construction. This leads to the inconsistency of coordinate system between urban and rural planning and land use planning, and it also leads to the inconsistency of coordinate system between the land transfer coordinate of the original land department and the coordinate issued by the planning department. Influenced by the length projection deformation, the parcel area calculated according to the coordinates issued by the two departments is not the same, resulting in contradictions.

\section{FEASIBILITY OF "MULTI-CONFORMITY"}

\subsection{Establishment of the Ministry of Natural Resources}

In 2018, the Ministry of Natural Resources was set up to incorporate the urban and rural planning responsibilities of housing and urban and rural construction management departments into it. According to this model, the urban and Rural Planning Bureau has been merged into the Natural Resources Bureau and a new Department of natural resources management has been set up. Taking advantage of the opportunity of planning departments and land departments to form natural resources departments, urban and rural planning have also to use CGCS2000 coordinate system to solve the problem of urban and rural planning and land use planning surveying and mapping datum directly.

\subsection{Application of Big Data}

The establishment of the natural resources department has solved the unification of the surveying and mapping datum of urban and rural planning and land use planning, but at the same time, it has produced the contradiction between the surveying and mapping datum of the natural resources department and the surveying and mapping datum of the housing and urban and rural construction management department, as well as the contradiction between the coordinate system of the real estate management department and the urban and rural planning department, which involve both natural resources departments. According to the development of big data, with the integration of Surveying and mapping geographic information and urban and rural planning, using the surveying and mapping power of newly formed natural resources department and the relevant management methods of confidential data processing, and with the cloud computing function of big data, the surveying and mapping data under CGCS2000 coordinate system are transformed into urban independent coordinate system and it should be provided to housing and urban and rural construction management departments to meet the requirements of urban surveying standards.

3.3 The Transformation between CGCS2000 and Independent Coordinate System of Bijie City

\subsubsection{CGCS2000 coordinate system}

CGCS2000 is based on the ITRF 97 reference frame with epoch of 2000.0 .

The basic constants of geodetic survey in 2000 national geodetic coordinate system are as follows:

Long half axis a=6 $378137 \mathrm{~m}$;

The gravitational constant $\mathrm{GM}=3.986004418 \times 10^{14} \mathrm{~m}^{3} \mathrm{~s}^{-2}$;

Flatness $\mathrm{f}=1 / 298.257222101$

Earth rotation angular velocity $\mathrm{X}=7.292115 \times 10 \mathrm{rads}$

\subsubsection{Urban Independent Coordinate System of Bijie Central City}

The urban independent coordinate system of Bijie central city is accomplished by using 2000 national geodetic coordinate system and ellipsoid expansion method. The ellipsoid expansion method does not change the flatness, only changes the long half axis of the ellipsoid. The projection surface elevation is equivalent to the ellipsoid expansion (expansion) to form a new ellipsoid, and the accuracy of the original results is not reduced in the process of establishing the coordinate system. Geodetic datum: Bijie central city independent coordinate system, referring to ellipsoid CGCS2000, central meridian $105^{\circ}$ 30 ', using projection surface elevation $1480 \mathrm{~m}$;

Elevation datum: 1985 National elevation datum;

Gravity datum: 2000 National Gravity Basic Network;

Quasi-geoid starting surface: 2000 national geodetic coordinate system referencing ellipsoid;

Long half axis: $\mathrm{a}=6379619.8877 \mathrm{~m}$.

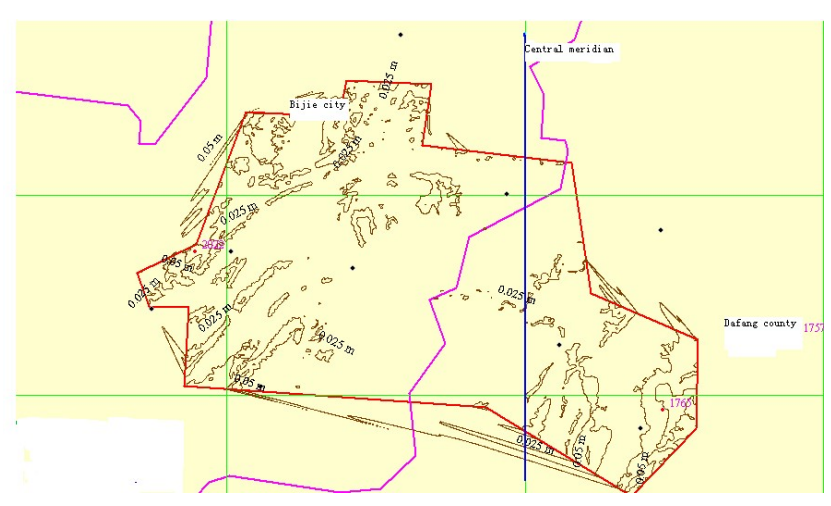

Fig. 1 Enlarged map of the length deformation exceeding the limit of Bijie central area independent coordinate system 
According to the statistics of $3 * 3$ " elevation grid data in the urban independent coordinate system area of Bijie central area, the maximum height is $2026.0 \mathrm{~m}$, the minimum height is $1148.0 \mathrm{~m}$, the maximum height difference is $878.0 \mathrm{~m}$, and the calculated average elevation is $1540 \mathrm{~m}$. Because it is located in the mountainous area and the height difference is large, the over-limited area of length deformation accounts for about $17.8 \%$ of the total area. To the west of the central meridian, the height of CGCS2000 is generally over $1640 \mathrm{~m}$. The distance from the central meridian can be increased appropriately according to the characteristics of length deformation; to the east of the central meridian, there is a relatively low-lying area in the southeast, belonging to the area of length deformation exceeding the limit, when the height of the earth is below 1320 $\mathrm{m}$ and over $1640 \mathrm{~m}$.

\section{TECHNICAL ROUTE TO BE ADOPTED}

\subsection{Unification of Multiple Surveying and Mapping Datums}

According to the unified requirements of the Ministry of Natural Resources, CGCS2000 coordinate system is used in urban and rural planning and land use planning. By coordinating with the government and utilizing the surveying and mapping technology of the natural resources department, the national economic development planning, ecological protection planning and other planning are unified into the CGCS2000 coordinate system to form a preliminary multi-dimensional integration and really fulfill the requirements of "a blueprint to the end".

In Bijie experimental area, the coordinate system is confused due to historical reasons. There exists 1954 Beijing coordinate system, 1980 Xi'an coordinate system, CGCS2000 coordinate system, Bijie City independent coordinate system, Bijie Central City independent coordinate system etc. Because many basic data do not specify the coordinate system, the coordinate system of topographic map can be judged according to the difference between the mapping coordinates and the coordinates on the map by calculating the control points of CGCS2000 coordinate system. Checking the quality of topographic map, if it is qualified, it will be converted to CGCS2000 coordinate system.

\begin{tabular}{|l|l|l|l|l|}
\hline & $\begin{array}{l}\text { Beijing } \\
\text { coordinate }\end{array}$ & $\begin{array}{l}\text { Xi'an } \\
\text { coordinate }\end{array}$ & $\begin{array}{l}\text { Independent } \\
\text { coordinate }\end{array}$ & $\begin{array}{l}\text { Old independent } \\
\text { coordinate }\end{array}$ \\
\hline $\begin{array}{l}\text { CGCS } \\
2000\end{array}$ & 61.6 & 112.9 & 62.7 & 49504 \\
\hline
\end{tabular}

\subsection{Provision of Coordinate Control Point}

Since the datum of natural resources system and the multi-conformity surveying mapping are both CGCS2000 coordinate system, it is necessary for the national coordinate system to provide the results of CGCS2000 coordinate system. For urban construction, the coordinates of CGCS2000 are converted into independent coordinate system of Bijie central area by using coordinate transformation software.

The coordinate conversion software interface is shown in Figure 2.

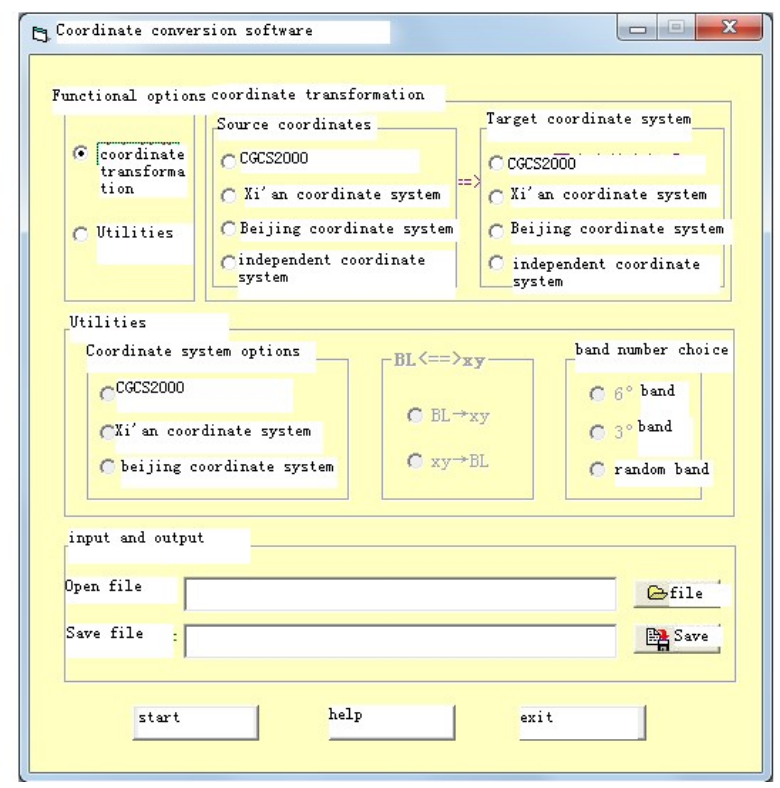

Fig. 2 Software for coordinate transformation of urban independent coordinate system of Bijie central area

\subsection{Provision of Topographic Maps}

The basis of a blueprint is the CGCS2000 coordinate system, its drawings can be provided directly without being restricted by the control system project. For urban construction departments and other departments, the drawings are provided by transforming coordinates of CGCS2000 grid into the urban independent coordinate system of Bijie central area. With the application of big data, the coordinate grid data of the area where the topographic map needs to be provided are selected, the seven-parameter transformation model is calculated, and the corresponding topographic map is transformed to be provided for the engineering construction unit by using the seven-parameter transformation model.

\section{ACKNOWLEDGEMENTS}

Application of error propagation law in engineering construction survey, number: Qian Ke He J Zi LKB [2012] No. 09, Moderator: Yong Lei supported by Guizhou Provincial University Joint Fund;

Surveying and mapping benchmark in the context of multiple compliance, number: Qian Jiao He KY Zi [2018] No. 071, Moderator: Yong Lei Supported by the science and technology top talent support program of Guizhou Colleges and Universities.

\section{REFERENCES}

Anonymous. Cooperation and dedication: Bijie Experimental Area expert advisory group for 20 years[M]. 2009.

Anonymous. 2016-2020. Outline of the 13th five year plan for national economic and social development of the people's Republic of China. Explanatory material [M]. 2016.

Shanbei Ke. Urban and rural integration all field control departmental collaboration-Notice on the implementation of the county (city) urban and rural master plan and the pilot 
work of "three compliance combination. explanation [J]. China Construction, 2014(4):22-25.

Website of National Bureau of Surveying and mapping. China launched CGCS2000 on July 1[J]. Land \& Resources, 2008(7):48-49.

Yong Lei, Lihui Wang, Zecheng Wang. on the establishment of urban independent coordinate system in Bijie City Center[J]. Journal of Liupanshui Normal University, 2014(6):13-16.

Anonymous. Profession Standard Of The People's Republic Of China:Code for urban surveyCJJ 8-99[M].2011.

Lei Qiu, Yuanhong Chen, Zhimin Yang. Change of The
Cadastral Parcel Area Caused by CGCS2000 coordinate system Conversion [J]. Urban Ggeotechnical Investigation \& Surveying, 2016(5):123-125.

Delun Huang. Buliding local independent coordinate system model based on CGCS2000 and analyzing example [D]. Xi an University of Science and Technology, 2013.

Zhanhui Yang, Xiaofeng Meng, Lian Liu. The design of CGCS2000 national geodetic coordinate system conversion program $[\mathrm{J}]$. Geomatics Technology and Equipment, 2012 (2): 53-54.

Revised December 2019 